University of South Carolina

Scholar Commons

6-12-2001

\title{
Increasing Power Density of LSGM-Based Solid Oxide Fuel Cells Using New Anode Materials
}

\author{
Kevin Huang \\ University of South Carolina - Columbia, huang46@cec.sc.edu \\ Jen-Hau Wan \\ John B. Goodenough
}

Follow this and additional works at: https://scholarcommons.sc.edu/emec_facpub

Part of the Mechanical Engineering Commons

\author{
Publication Info \\ Published in Journal of The Electrochemical Society, Volume 148, Issue 7, 2001, pages A788-A794. \\ (C) Journal of The Electrochemical Society 2001, The Electrochemical Society. \\ (C) The Electrochemical Society, Inc. 2001. All rights reserved. Except as provided under U.S. copyright law, \\ this work may not be reproduced, resold, distributed, or modified without the express permission of The \\ Electrochemical Society (ECS). The archival version of this work was published in Journal of The \\ Electrochemical Society. \\ Publisher's Version: http://dx.doi.org/10.1149/1.1378289 \\ Huang, K., Wan, J. H., \& Goodenough, J. B. (2001). Increasing Power Density of LSGM-Based Solid Oxide \\ Fuel Cells Using New Anode Materials. Journal of The Electrochemical Society, 148 (7), A788- A794. \\ http://dx.doi.org/10.1149/1.1378289
}

This Article is brought to you by the Mechanical Engineering, Department of at Scholar Commons. It has been accepted for inclusion in Faculty Publications by an authorized administrator of Scholar Commons. For more information, please contact digres@mailbox.sc.edu. 


\title{
Increasing Power Density of LSGM-Based Solid Oxide Fuel Cells Using New Anode Materials
}

\author{
Keqin Huang,",a Jen-Hau Wan,* and John B. Goodenough \\ Texas Materials Institute, The University of Texas at Austin, Austin, Texas 78712, USA
}

\begin{abstract}
Chemical reactions between the superior perovskite oxide-ion conductor Sr- and Mg-doped $\mathrm{LaGaO}_{3}$ (LSGM), $\mathrm{CeO}_{2}$, and $\mathrm{NiO}$ have been studied by powder X-ray diffraction. The results showed that an extensive reactivity occurs as a result of La migration driven by a gradient of La chemical activity. La migration across the LSGM/electrode interfaces in a fuel cell leads to the formation of resistive phases at the interface, either $\mathrm{LaSrGa}_{3} \mathrm{O}_{7}$ or $\mathrm{LaSrGaO}_{4}$. Use of $40 \mathrm{~mol} \% \mathrm{La}_{2} \mathrm{O}_{3}$-doped $\mathrm{CeO}_{2}$ as an interlayer between anode and electrolyte as well as in the NiO-containing anode prevents all reactions found. Consequently, the air- $\mathrm{H}_{2}$ cell maximum power density was increased to nearly $900 \mathrm{~mW} / \mathrm{cm}^{2}$ at $800^{\circ} \mathrm{C}$ with a $600 \mu \mathrm{m}$ thick LSGM electrolyte. No sign of degradation was observed at $800^{\circ} \mathrm{C}$ over 2 weeks for an interlayered cell under a loading current density of $250 \mathrm{~mA} / \mathrm{cm}^{2}$.

(c) 2001 The Electrochemical Society. [DOI: 10.1149/1.1378289] All rights reserved.
\end{abstract}

Manuscript submitted November 1, 2000; revised manuscript received January 23, 2001. Available electronically June 12, 2001.

Since the discovery of the superior perovskite oxide-ion conductor $\mathrm{Sr}$ - and $\mathrm{Mg}$-doped $\mathrm{LaGaO}_{3}$, hereinafter referred to as LSGM, more than five years ago, ${ }^{1,2}$ more and more studies have shown that LSGM is an excellent electrolyte candidate for reduced-temperature solid oxide fuel cells (RTSOFCs). Among these reports, ${ }^{3-12}$ single ceramic fuel cell tests using a thick-film $(>500 \mu \mathrm{m})$ LSGM as the electrolyte have demonstrated a most encouraging cell performance at an operating temperature $T_{\mathrm{op}}<800^{\circ} \mathrm{C}^{5,6}$ The major contributions to the high power density exhibited by the LSGM-based fuel cells are attributed to the improvement of the electrolyte conductivity and, more important, its exceptional structural and chemical compatibility with perovskite cathode materials that are mixed electronic and oxide-ion conductors (MEOCs). The chemical compatibility with an MEOC cathode is also regarded as a major advantage of the LSGM electrolyte over its competitor, yttria-stabilized $\mathrm{ZrO}_{2}$ (YSZ); the YSZ usually reacts with $\mathrm{La}$ (Sr)-containing perovskite cathode materials during fabrication by forming resistive pyrochlore $\mathrm{La}_{2} \mathrm{Zr}_{2} \mathrm{O}_{7}$ and perovskite $\mathrm{SrZrO}_{3}$ phases at the cathode/electrolyte interface. These interfacial reactions are even more favorable when an MEOC such as Sr-doped $\mathrm{LaCoO}_{3-\delta}$ (LSCo), a proven excellent cathode for oxygen reduction, is used. ${ }^{13}$ To alleviate these unwanted chemical reactions to the greatest extent possible, a balance between chemical reactivity and electrocatalytic activity must be made for the selection of cathode materials for $\mathrm{ZrO}_{2}$-based SOFCs. One of the viable solutions is to choose the solely electron-conducting $\mathrm{Sr}$-doped $\mathrm{LaMnO}_{3}$ (LSM) as the cathode material; it has reasonably good electrocatalytic activity for oxygen reduction, a close thermal expansion match to and little chemical reactivity with a $\mathrm{ZrO}_{2}$-based electrolyte. In this case, however, it is necessary to fabricate a porous electrode, and the electrode performance depends largely on how well the linear triplephase (gas-electrode-electrolyte) boundary length is established. In other words, the LSM electrode is extremely sensitive to the microstructure morphology and the stability of this morphology under operating conditions as in the case of the common composite anode. ${ }^{14,15}$ Because of the outstanding chemical and structural compatibility of LSGM with most perovskite cathode materials, the designer of an LSGM-based SOFCs can freely choose the best MEOCs such as LSCo, as the cathode material. Under such circumstances, the advantages of a mixed conducting material as an electrode for an electrochemical cell are fully utilized.

On the anode/electrolyte interface, however, the composite anode YSZ + NiO in $\mathrm{ZrO}_{2}$-based SOFCs showed much better chemical compatibility with YSZ than the anode LSGM $+\mathrm{NiO}$ in

\footnotetext{
* Electrochemical Society Student Member.

${ }^{\text {a }}$ Present address: Siemens Westinghouse Power Corporation, Pittsburgh, PA 15235, USA.
}

LSGM-based SOFCs. Our previous study ${ }^{3}$ indicated that the LSGM $+\mathrm{NiO}$ composite anode has a fairly low initial overpotential that quickly increases with time to a very high level upon current draining through the cell. Replacement of the LSGM in the LSGM $+\mathrm{NiO}$ composite anode with $20 \mathrm{~mol} \% \quad \mathrm{Sm}_{2} \mathrm{O}_{3}$-doped $\mathrm{CeO}_{2}$ (SDC20), one of the best oxide-ion conductors in $\mathrm{CeO}_{2}$-based electrolytes, improved the power stability dramatically, but it gave somewhat lower power density compared to the initial power density exhibited by the LSGM $+\mathrm{NiO}$ anode. It was found in a later study that the LSGM reacts readily with the NiO during the anode preparation and cell operation. ${ }^{4,5}$ To eliminate this reaction, we introduced a Ni-free interlayer SDC20 between LSGM and anode SDC20 $+\mathrm{NiO}$, and the power density of the cell was further increased from 450 to $550 \mathrm{~mW} / \mathrm{cm}^{2}$ at $800^{\circ} \mathrm{C}$ with an extended stable power output over $1500 \mathrm{~h}^{5}$

Although the performance of LSGM-based fuel cells has been improving progressively in the past 5 years in our laboratory ${ }^{3-7}$ as well as in other groups, ${ }^{8-12}$ a thorough understanding of the chemical reactions between LSGM and a Ni-containing $\mathrm{CeO}_{2}$-based anode is still lacking. Recently, Hrovat et al. ${ }^{16-20}$ systematically studied phase relationships between $\mathrm{La}_{2} \mathrm{O}_{3}, \mathrm{Ga}_{2} \mathrm{O}_{3}, \mathrm{CeO}_{2}$, and various transition-metal oxides. Their studies showed evidence of reactions between $\mathrm{La}_{2} \mathrm{O}_{3}, \mathrm{Ga}_{2} \mathrm{O}_{3}, \mathrm{NiO}$, and $\mathrm{CeO}_{2}$. If this is true, an improper selection of $\mathrm{CeO}_{2}$-based anode materials could cause a compositional alteration of the LSGM as a result of La diffusion into the $\mathrm{CeO}_{2}$-based anode, which would lead to the formation of resistive phases such as $\mathrm{LaSrGa}_{3} \mathrm{O}_{7}$ at the anode/electrolyte interface. Prevention of the La cation from crossing the electrode/electrolyte interface could turn out to be the key issue to prevent these unwanted interfacial reactions and therefore to increase the cell power density and long-term stability.

In this paper, we report investigations of chemical reactions between the LSGM, NiO, and doped $\mathrm{CeO}_{2}$ involved in LSGM-based SOFCs. Effective measures to prevent the interactions are proposed and verified in single-cell tests. Several mixed-conductor perovskites or perovskite-related oxides were also examined as cathode materials. As a result of using the best MEOC as the cathode and a chemically improved anode composite, the maximum power density has been increased to $900 \mathrm{~mW} / \mathrm{cm}^{2}$ at $800^{\circ} \mathrm{C}$ with a $600 \mu \mathrm{m}$ thick LSGM electrolyte in a single cell utilizing air and $\mathrm{H}_{2}+3 \% \mathrm{H}_{2} \mathrm{O}$ as the oxidant and fuel, respectively.

\section{Experimental}

Sample preparation.--In this study, the electrolyte composition $\mathrm{La}_{0.8} \mathrm{Sr}_{0.2} \mathrm{Ga}_{0.83} \mathrm{Mg}_{0.17} \mathrm{O}_{2.815}$ (LSGM) was chosen as our previous study $^{21}$ has shown it to be optimal. Well-sintered pellets $(>99 \%$ dense) were obtained after a final sintering at $1450^{\circ} \mathrm{C}$ for $24 \mathrm{~h}$, they were subsequently ground with a diamond wheel to a thickness greater than $500 \mu \mathrm{m}$ for our fuel cell tests. 
Table I. Electrode preparation conditions.

\begin{tabular}{|c|c|c|c|c|c|c|}
\hline Compositions & Symbol & Purpose & Synthesis & Decomp $T$ & Sintering $T$ & Structures \\
\hline $\mathrm{La}_{0.6} \mathrm{Sr}_{0.4} \mathrm{CoO}_{3-\delta}$ & LSCo40 & Cathode & Pechini & $750^{\circ} \mathrm{C}$ & $1250^{\circ} \mathrm{C}$ & Rhombohedral \\
\hline $\mathrm{La}_{0.8} \mathrm{Sr}_{0.2} \mathrm{Co}_{0.8} \mathrm{Ni}_{0.2} \mathrm{O}_{3-\delta}$ & LSCN & Cathode & Pechini & $750^{\circ} \mathrm{C}$ & $1300^{\circ} \mathrm{C}$ & Rhombohedral \\
\hline $\mathrm{La}_{0.7} \mathrm{Sr}_{0.3} \mathrm{Fe}_{0.8} \mathrm{Ni}_{0.2} \mathrm{O}_{3-\delta}$ & LSFN & Cathode & Pechini & $750^{\circ} \mathrm{C}$ & $1400^{\circ} \mathrm{C}$ & Rhombohedral \\
\hline $\mathrm{La}_{0.85} \mathrm{Sr}_{0.15} \mathrm{MnO}_{3}$ & LSM15 & Cathode & Pechini & $750^{\circ} \mathrm{C}$ & $1400^{\circ} \mathrm{C}$ & Orthorhombic \\
\hline $\mathrm{Ce}_{0.8} \mathrm{Sm}_{0.2} \mathrm{O}_{1.9}$ & SDC20 & Interlayer & Pechini & $750^{\circ} \mathrm{C}$ & $1450^{\circ} \mathrm{C}$ & Fluorite Cubic \\
\hline $\mathrm{Ce}_{0.6} \mathrm{La}_{0.4} \mathrm{O}_{1.8}$ & LDC40 & Interlayer & Pechini & $750^{\circ} \mathrm{C}$ & $1450^{\circ} \mathrm{C}$ & Fluorite Cubic \\
\hline
\end{tabular}

Both the cathode and the anode materials were synthesized by a wet-chemical route. ${ }^{22}$ The Pechini process, based on using a carboxylate group such as citric acid as the chelating agent, was selected for the synthesis of precursors of all electrode powders except for $\mathrm{SrCo}_{0.8} \mathrm{Fe}_{0.2} \mathrm{O}_{3-\delta}(\mathrm{SCF})$. The exact composition of each electrode and their synthesis condition are summarized in Table I. Single-phase SCF proved difficult to make by a normal Pechini process. The hexagonal $\mathrm{SrCoO}_{2}$ that contains no oxygen vacancies was always preferentially formed in addition to the desired perovskite phase. We attributed this behavior to an uneven distribution of $\mathrm{Sr}^{2+}$ in the solution as a result of only partial coordination of some of the $\mathrm{Sr}^{2+}$ ions by the relatively weak chelation ability of the carboxylate ligands in citric acids. Therefore, we chose ethylenediaminetetra-acetic acid (EDTA) as the chelating agent since all cations of the SCF coordinate strongly with EDTA according to their larger formation constants for chelation. The use of EDTA suppressed the segregation of $\mathrm{Sr}^{2+}$ in the Pechini process, and well-crystallized, single-phase cubic SCF powders were obtained at temperatures as low as $1000^{\circ} \mathrm{C}$.

The crystal structures of the aforementioned electrolyte and electrode powders were examined at room temperature by X-ray diffraction (XRD) with a Philips PW1729 diffractometer operating with $\mathrm{Cu}$ $\mathrm{K} \alpha$ radiation and Ni filter. For accurate determination of lattice parameters, synthetic silicon powder was used as the internal standard.

The chemical reactivity between LSGM, NiO, and $\mathrm{CeO}_{2}$ doped with $\mathrm{Sm}$ or La was primarily studied by powder XRD. The LSGM powders were mixed with $\mathrm{NiO}$ and doped $\mathrm{CeO}_{2}$, respectively, at a ratio of $1: 1$ ( $v o l \%$ or wt $\%$ ), followed by firing at temperatures above $1350^{\circ} \mathrm{C}$ for several hours. The XRD patterns of the resulting mixtures were carefully analyzed, and the phases as well as structures were determined with the Jade 5.0 software (from Materials Data Inc.).

Single fuel-cell tests.-For fabricating a single cell with an interlayer between the anode and electrolyte, the interlayer is usually first coated on one side of an $18 \mathrm{~mm}$ diam, >500 $\mu \mathrm{m}$ thick LSGM electrolyte disk by screen printing a slurry of the interlayer ink and baking at $1300^{\circ} \mathrm{C}$ in air for $1 \mathrm{~h}$. The importance of this precalcination is to ensure a good bonding of the interlayer to the LSGM and to have a dense microstructure so that the possible Ni diffusion from the anode through the interlayer can be prohibited. The composite anode was then screen printed on the top of the interlayer (or directly on the disk in the absence of an interlayer) followed by adding a $\mathrm{Pt}$ mesh as the current collector and calcining at $1350^{\circ} \mathrm{C}$ for an additional $1 \mathrm{~h}$. A similar screen printing procedure was also used to make the cathode coating, but with a much lower calcining temperature, typically at 1100 to $1150^{\circ} \mathrm{C}$ for $1 \mathrm{~h}$ depending on the cathode material. The effective electrode area of the cell was $0.24 \mathrm{~cm}^{2}$. Reference electrodes of the same materials as the working electrodes were used to monitor the overpotentials of the cathode and anode in the cell configuration previously described. ${ }^{5,6}$ In such a configuration, we were able to measure simultaneously the cell voltage and the electrode overpotentials at different current densities.
A double-layer sealing design was applied in all single-cell tests. For the internal sealing, a Pyrex glass ring was placed between the cell and the supporting $\mathrm{Al}_{2} \mathrm{O}_{3}$ tube. A slurry, which was made by mixing Duco cement and a special glass powder developed in our laboratory with acetone, was pasted on the outside of the Pyrex glass ring to serve as the external sealing. The applied glasses are expected to soften at $800^{\circ} \mathrm{C}$ so as to seal the whole cell in situ. In our tests, the assembled test cells are usually placed in the hot zone of a vertical furnace with air directly supplied to the cathode surface at a rate of $\mathrm{mL} / \mathrm{min}$ and water-moistened hydrogen $(\sim 3 \%$ steam at $30^{\circ} \mathrm{C}$ ) to the anode surface at a rate of $40-60 \mathrm{~mL} / \mathrm{min}$. Test cells are normally purged with hydrogen gas for $1 \mathrm{~h}$ before the temperature ramps up. The performance measurements are typically carried out in the temperature range $600^{\circ} \mathrm{C}<T<800^{\circ} \mathrm{C}$ with an interval of $50^{\circ} \mathrm{C}$, and a constant potential is provided by an EG\&G potentiostat/ galvanostat model 273 running on a homemade LabView program. During a typical measurement, the cell voltage is varied from opencircuit voltage $(\mathrm{OCV})$, usually $1.1 \mathrm{~V}$ at $800^{\circ} \mathrm{C}$, to $0.4 \mathrm{~V}$ and back to $\mathrm{OCV}$ in a total of 40 steps and holding $10 \mathrm{~s}$ at each point.

\section{Results and Discussion}

Reactivity of LSGM with $\mathrm{CeO}_{2}$-based materials.-The $\mathrm{CeO}_{2}$-based materials are well-known oxide-ion conductors having the cubic fluorite structure. Pure $\mathrm{CeO}_{2}$ can form a wide range of solid solutions with most of the rare- and alkaline-earth oxides. Although $\mathrm{CeO}_{2}$-based oxides may not be appropriate solid electrolytes for SOFCs due to the reduction of $\mathrm{Ce}^{4+}$ to $\mathrm{Ce}^{3+}$ in fuel atmospheres at elevated temperatures, more and more results are demonstrating that they can be performance-enhancing oxides in the composite anodes containing $\mathrm{Ni}$ for SOFCs. The mixed n-type electron and oxide-ion conduction as a result of the $\mathrm{Ce}^{4+} / \mathrm{Ce}^{3+}$ mixed valence in reducing atmospheres and a rapid $\mathrm{H}_{2}$ oxidation at the surface are responsible for the observed enhanced anode performance.

Generally, $20 \mathrm{~mol} \% \mathrm{Sm}_{2} \mathrm{O}_{3}$-doped $\mathrm{CeO}_{2}$, hereinafter referred to as SDC20, has been chosen in many studies because of its highest oxide-ion conductivity among the $\mathrm{CeO}_{2}$ systems. As a replacement of $\mathrm{YSZ}$ in the composite anode, a doped- $\mathrm{CeO}_{2}+\mathrm{NiO}$ composite anode has been reported to improve significantly the performance of $\mathrm{ZrO}_{2}$-based SOFCs. ${ }^{23}$ But concerns may arise when used in LSGMbased SOFCs. A previous study ${ }^{24}$ has shown a solid solubility of up to $50 \mathrm{~mol} \%$ of $\mathrm{LaO}_{1.5}$ in $\mathrm{CeO}_{2}$. Therefore, a La diffusion from the LSGM into the SDC20 could be induced as a result of the gradient of the La chemical activity across the anode/electrolyte interface during anode fabrication. This in turn could lead to a La deficiency in the LSGM, which is reflected in the phase diagram shown in Fig. $1^{20}$ by the appearance of a resistive phase, $\mathrm{LaSrGa}_{3} \mathrm{O}_{7}$, in addition to the desired cubic perovskite phase. The existence of the insulating phase $\mathrm{LaSrGa}_{3} \mathrm{O}_{7}$ at the electrode/electrolyte interface would deteriorate the fuel-cell performance. To prove the above hypothesis, XRD was conducted to identify the phases after firing an intimate mixture of the LSGM and the SDC20 at high temperatures. Such an 

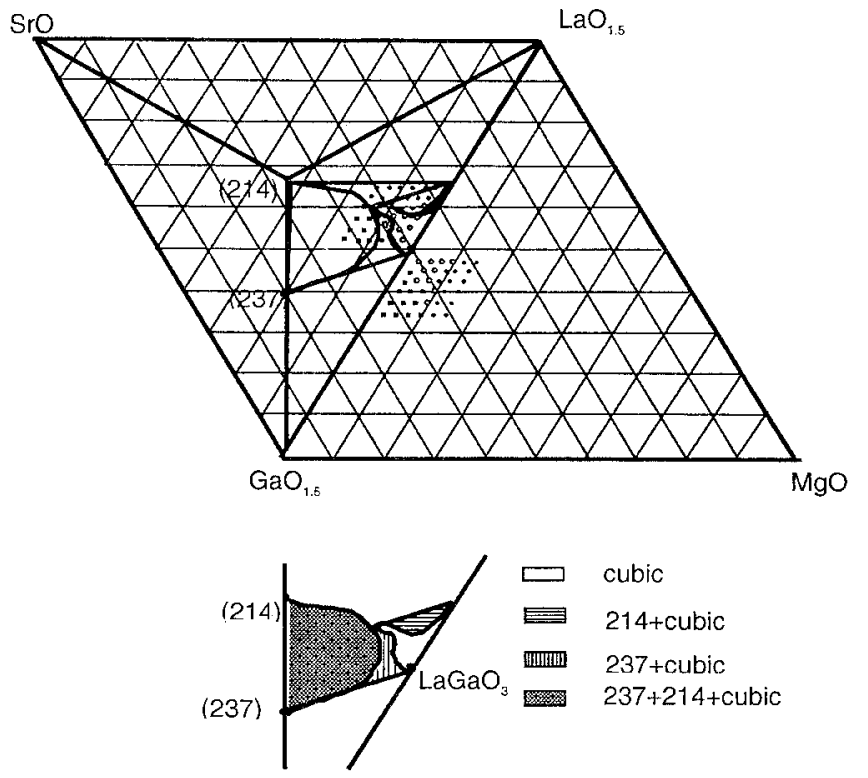

Figure 1. Phase diagram illustrating $\mathrm{LaO}_{1.5}-\mathrm{SrO}-\mathrm{GaO}_{1.5}$ phase relationships.

$\mathrm{XRD}$ pattern is shown in Fig. 2. Clearly, a large amount of $\mathrm{LaSrGa}_{3} \mathrm{O}_{7}$ phase is embedded in the matrix of the LSGM and SDC20 cubic phases, which agrees well with our hypothesis. In a subsequent attempt to alleviate the La diffusion, we proposed use of $\mathrm{La}$ as a substitute in the $\mathrm{CeO}_{2}$ instead of $\mathrm{Sm}$ so that the gradient of the La chemical activity between the LSGM and $\mathrm{CeO}_{2}$ can be minimized to zero. This strategy proved to be effective in preventing the La diffusion. Figure 3 illustrates a set of XRD patterns of equalweight mixtures of the LSGM and $\mathrm{La}_{2} \mathrm{O}_{3}$-doped $\mathrm{CeO}_{2}$ (LDC) after firing at high temperatures. The mixture with higher La content in $\mathrm{CeO}_{2}$, i.e., $50 \mathrm{~mol} \%$ (LDC50), precipitated another resistive phase, $\mathrm{LaSrGaO}_{4}$, in addition to the matrix cubic phases. It is expected from our phase diagram, Fig. 1, that a two-phase region consisting of $\mathrm{LaSrGaO}_{4}$ and the cubic phase would be formed if the La concentration in the LSGM is enriched due to La diffusion from LDC50 into the LSGM. On the other hand, with lower La content in the $\mathrm{CeO}_{2}$, i.e., $35 \mathrm{~mol} \%$ (LDC35), the mixture produced the $\mathrm{LaSrGa}_{3} \mathrm{O}_{7}$ as in the case of the SDC20 as a result of La diffusion from the LSGM into the LDC35. It is exactly at the equal La concentration in the LSGM and the LDC, namely, $40 \mathrm{~mol} \%$ (LDC40), that neither $\mathrm{LaSrGaO}_{4}$ nor $\mathrm{LaSrGa}_{3} \mathrm{O}_{7}$ is detected in the XRD pat-

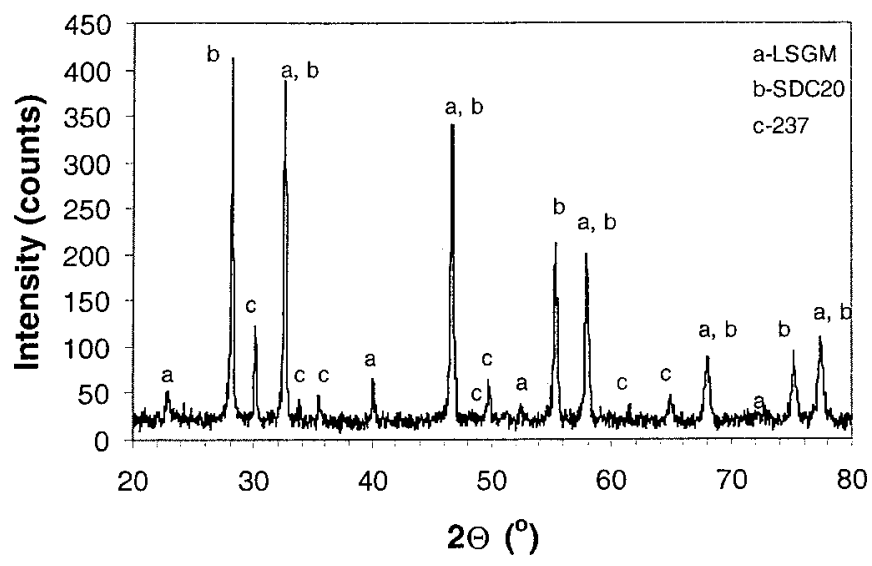

Figure 2. XRD pattern of a mixture consisting of SDC20 and LSGM (1:1 wt \%) after firing at $1450^{\circ} \mathrm{C}$ for $10 \mathrm{~h}$. The notation 237 represents the compound $\mathrm{LaSrGa}_{3} \mathrm{O}_{7}$.

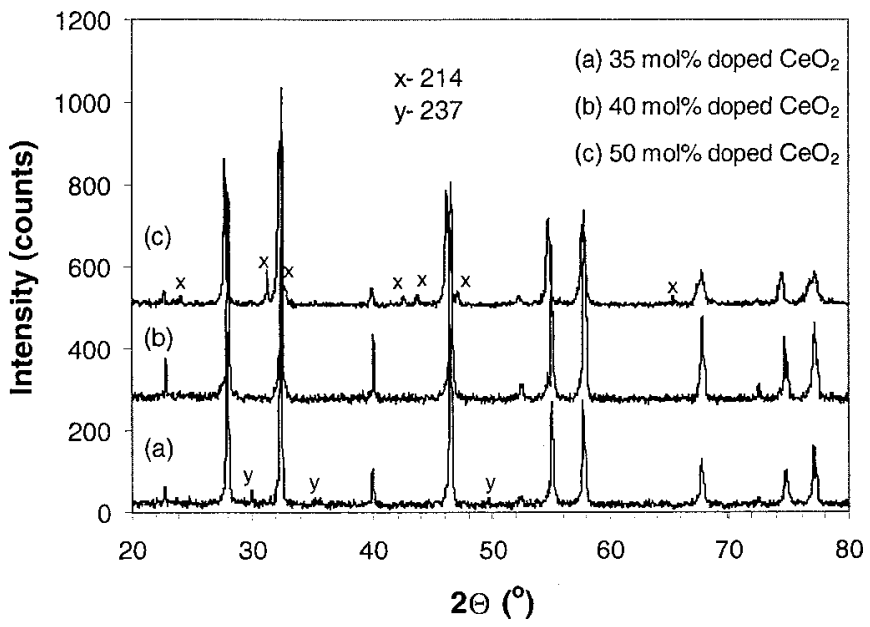

Figure 3. XRD patterns of mixtures consisting of LSGM and various $\mathrm{La}_{2} \mathrm{O}_{3}$-doped $\mathrm{CeO}_{2}$ after firing at $1350^{\circ} \mathrm{C}$ for $5 \mathrm{~h}$. The notation 214 represents the compound $\mathrm{LaSrGaO}_{4}$. Unmarked peaks belong to LDC or LSGM.

terns, indicating no reactivity between LSGM and LDC at this particular content. Therefore, we have adopted LDC40 $+\mathrm{NiO}$ and LDC40, respectively, as the composite anode and the anode interlayer in our following single-cell tests.

Reactivity of LSGM with NiO.-Because it is feasible for La and $\mathrm{Ga}$ in the LSGM to react thermodynamically with $\mathrm{NiO}$ at elevated temperatures, we also studied the reactivity between the LSGM and $\mathrm{NiO}$. Powder XRD was performed as a primary tool to analyze the phase compositions in the mixtures. Figure $4 \mathrm{a}$ demonstrates the XRD pattern of the LSGM and NiO mixture (1:1 vol \%, consisting of approximately $60 \mathrm{wt} \% \mathrm{NiO}$ ). In addition to the phases belonging to $\mathrm{NiO}$ and LSGM, two more new phases, $\mathrm{LaNiO}_{3}$ and $\mathrm{LaSrGa}_{3} \mathrm{O}_{7}$, were observed in the pattern. The formation of $\mathrm{LaSrGa}_{3} \mathrm{O}_{7}$ is not surprising according to the phase diagram because some of the lanthanum in the LSGM has been consumed to react with NiO. However, the formation of $\mathrm{LaNiO}_{3}$ is somehow beyond our expectation. Thermodynamically speaking, $\mathrm{LaNiO}_{3}$ is not stable above $1200^{\circ} \mathrm{C},{ }^{25-27}$ it decomposes into the stable phases $\mathrm{La}_{2} \mathrm{NiO}_{4}$ and $\mathrm{NiO}$ accompanied by an evolution of pure oxygen. One possible explanation of the observed presence of $\mathrm{LaNiO}_{3}$ in the final product would be that the kinetics of the decomposition reaction is relatively slow. A schematic illustration of the simplified $\mathrm{LaO}_{1.5}-\mathrm{GaO}_{1.5}-\mathrm{NiO}$ phase diagram is shown in Fig. 4b. The shaded area represents the common anode composition where either $\mathrm{LaNiO}_{3}$ or $\mathrm{NiGa}_{2} \mathrm{O}_{4}$ can be formed depending on the actual composition. Nevertheless, the initial LSGM composition would be changed no matter which oxide is yielded; this change eventually leads to the formation of the unwanted resistive phase $\mathrm{LaSrGa}_{3} \mathrm{O}_{7}$, which is not reducible once it is formed. Therefore, as in the case of $\mathrm{CeO}_{2}$, to keep the compositional uniformity of the LSGM, the reactivity between the LSGM and NiO must be inhibited.

Reactivity of LDC4O with $\mathrm{NiO}$.- - Although the reactions between LDC40 and NiO do not seem to be as technologically important as those of LSGM with $\mathrm{CeO}_{2}$ and $\mathrm{NiO}$, an understanding of the phase relationship would help to avoid a possible negative impact caused by chemical interdiffusion. Similar to Fig. $4 \mathrm{~b}$, the phase relationships in the $\mathrm{LaO}_{1.5}-\mathrm{CeO}_{2}-\mathrm{NiO}$ system are illustrated in Fig. 5a. It is clear that the tie lines are between $\mathrm{NiO}$ and $\mathrm{LaO}_{1.5}-\mathrm{CeO}_{2}$ solid solution. No reaction products were found between $\mathrm{CeO}_{2}$ and $\mathrm{NiO}$. The shaded area, which represents the regular anode composition used in our fuel-cell tests, falls well into the two-phase region. As long as the $\mathrm{La}_{2} \mathrm{O}_{3}$ doping level does not exceed $50 \mathrm{~mol} \%$, it will maintain a two-phase mixture, which fulfills the phase requirement 


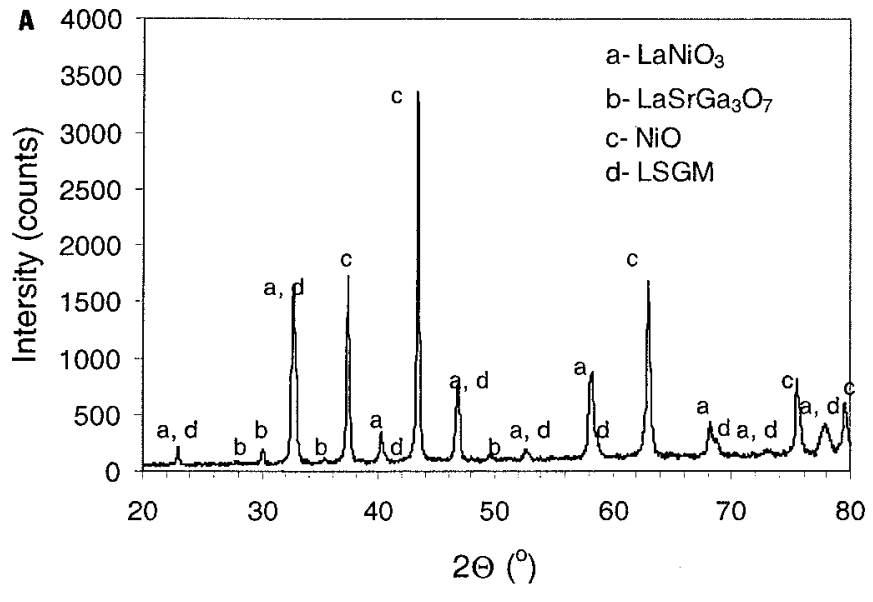

B

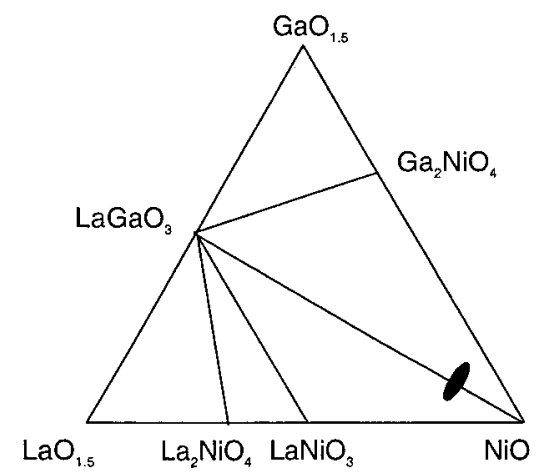

Figure 4. (a) XRD pattern of the mixture consisting of LSGM and $\mathrm{NiO}(1: 1$ vol \%) after firing at $1400^{\circ} \mathrm{C}$ for $1 \mathrm{~h}$. (b) Simplified phase diagram of the $\mathrm{LaO}_{1.5}-\mathrm{GaO}_{1.5}-\mathrm{NiO}$ system.

for the composite anode materials. The phase analysis in Fig. 5a was further verified by powder XRD, Fig. 5b, which showed no other phases than the LDC40 and $\mathrm{NiO}$ found in the pattern.

Single-cell performance.-Any of the components included in an SOFC may become performance-influencing factors. Electrode and electrolyte materials as well as their preparation conditions are the immediate examples. Studies on how preparation conditions impact on the cell performance would help to find the best composition as well as condition to fabricate cells. Therefore, the effects of the electrode materials and of their preparation conditions on cell performance were studied with a particular emphasis on the anode interlayer.

Anode materials.-As discussed above, there is a great potential for LSGM to react with SDC20 at elevated temperatures. Therefore, the anode overpotential used for evaluating the anode performance could be dependent on the calcining conditions under which various amounts of insulating phases are generated. This sensitivity to the preparation conditions is clearly seen in Fig. 6, where the overpotential, $\eta_{\mathrm{a}}$, of the composite anode SDC20 $+\mathrm{NiO}$ was measured at $800^{\circ} \mathrm{C}$ as a function of current density. It is apparent that too high a calcining temperature yielded too much insulating phase while too low a calcining temperature cannot provide a good anode-electrolyte bonding; in both cases the anode is degraded and a compromise must be struck between the amount of insulating phase formed and the strength of the interfacial mechanical bonding that is achieved.

To alleviate this problem, we proposed the use of $\mathrm{La}_{2} \mathrm{O}_{3}$-doped $\mathrm{CeO}_{2}$ as a replacement of $\mathrm{Sm}_{2} \mathrm{O}_{3}$-doped $\mathrm{CeO}_{2}$ in the composite anode containing $\mathrm{NiO}$. The LDC40 was selected so as to maintain an iso-activity of La across the electrolyte/anode interface. In addition, to prevent the reaction between $\mathrm{NiO}$ and the LSGM, we introduced a Ni-free interlayer LDC40 between the LSGM and the LDC40
A
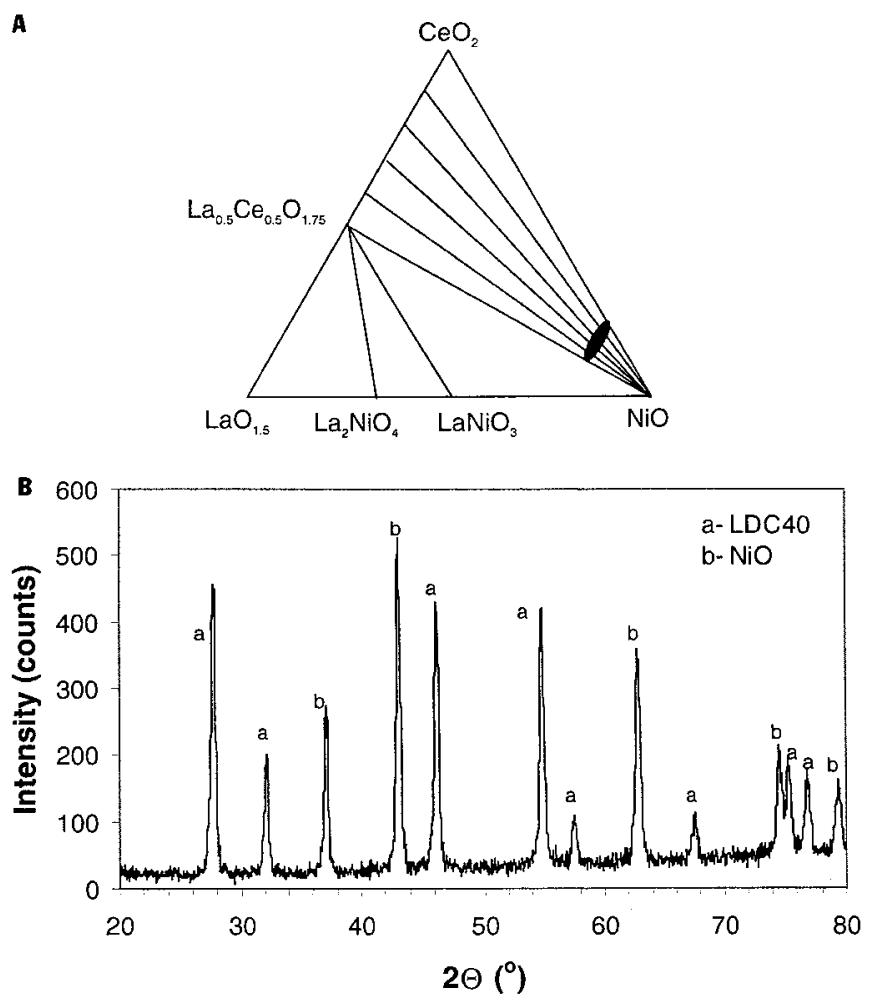

Figure 5. (a) Simplified phase diagram of the $\mathrm{LaO}_{1.5}-\mathrm{CeO}_{2}-\mathrm{NiO}$ system. (b) XRD pattern of the mixture consisting of LDC40 and $\mathrm{NiO}(1: 1 \mathrm{vol} \%)$ after firing at $1400^{\circ} \mathrm{C}$ for $1 \mathrm{~h}$.

$+\mathrm{NiO}$ anode. The significance of this anode interlayer is shown in Fig. 7, where the anode overpotentials vs. the cell current density at different temperatures with and without the interlayer are compared. The anode overpotential with the LDC40 interlayer has been decreased by more than $40 \%$ of the noninterlayered anode. This reduction leads to a dramatic increase in the cell power density.

Cathode materials.-From an electrochemical standpoint, a mixed electronic and oxide-ion conduction in an electrode is the most desirable property for accelerating the rate of reduction or oxidation at the electrode provided that the mixed conductors promote the surface reactions. The electrode reactions for the mixed conducting electrodes are only restricted to the gas-solid two-phase interface; in contrast, the reactions occur at a gas-solid-solid triple-phase bound-

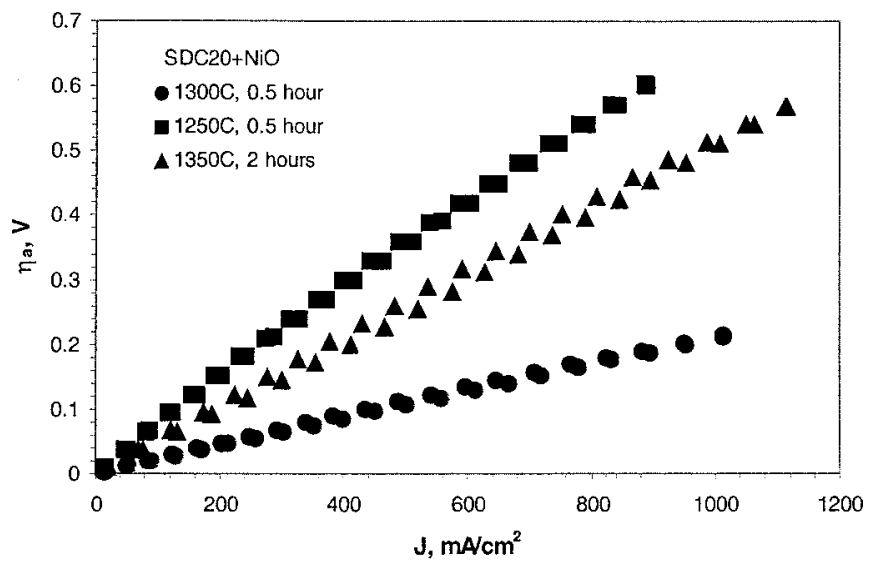

Figure 6. Effect of preparation conditions of anode SDC20 $+\mathrm{NiO}$ on the overpotential measured at $800^{\circ} \mathrm{C}$. 


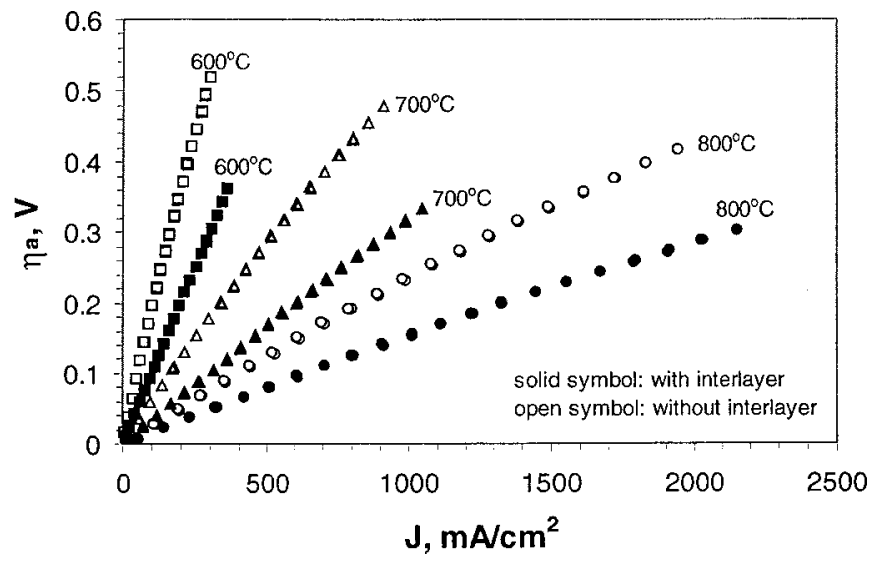

Figure 7. Comparison of overpotentials produced by the anode LDC40 $+\mathrm{NiO}$ with and without interlayer $\mathrm{LDC} 40$ at various temperatures.

ary for a solely electron-conducting electrode. The transport of oxide ions through a MEOC electrode and across the cathode/ electrolyte interface have been reported to be sufficiently fast; ${ }^{28,29}$ the dioxygen dissociation on the gas-solid surface is usually the only rate-limiting step. Increasing the electrode areas is the most effective way of enhancing the oxygen exchange rate at the gas-solid interface. Therefore, a much lower electrode overpotential is normally observed as a result of the fast overall rate of transport of oxide ions provided by the MEOC electrode. For an LSGM electrolyte, the cathode performance can be evaluated on a variety of known MEOCs because of the compatibility of LSGM with these perovskites.

Figure 8 compares the overpotentials of various cathode materials in a single-cell configuration containing a cathode layer deposited directly on the LSGM. It is clear that the SCF and the LSM15 gave, respectively, the lowest and the highest overpotentials among those tested. It is not surprising to see this trend because many researchers have concluded that SCF produces the highest oxygen flux of all the cobalt-containing perovskites ${ }^{30}$ due to its high mixed conductivity. LSM15 is solely an electronic conductor with a lower conductivity. Corresponding impedance spectroscopy studies of a symmetrical cell with the LSGM as the electrolyte and the above materials as the electrodes came to the same conclusion, i.e., the SCF and the LSM15 have the smallest and the highest electrode resistance, respectively, with all other cathode materials between

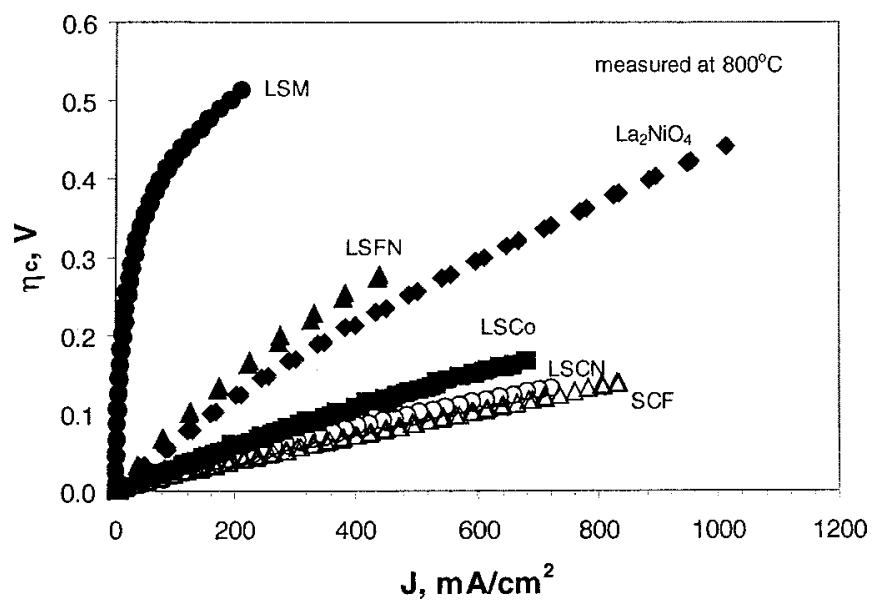

Figure 8. Comparison of the cathode overpotentials at $800^{\circ} \mathrm{C}$ for several cathode films.

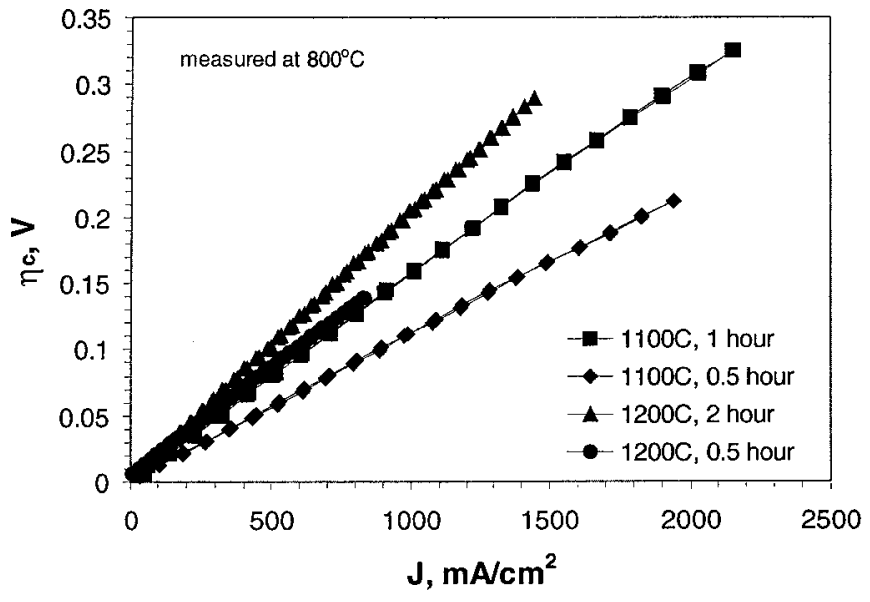

Figure 9. Effect of cathode preparation conditions on the overpotential at $800^{\circ} \mathrm{C}$.

them. ${ }^{6}$ In practice, LSM15 is made porous to give it a better performance.

Similar to the anode, the cathode overpotential is also a function of preparation conditions. This dependence is illustrated in Fig. 9, where the SCF overpotentials as a function of current density and preparation conditions are shown. The data suggest that the lower the calcination temperature and the shorter the calcination time, the better the performance. If La diffusion is true for the anode, it may be equally true for the cathode. An independent study was then carried out in which SCF and $\mathrm{La}_{0.8} \mathrm{Sr}_{0.2} \mathrm{CoO}_{3-\delta}$ (LSCo20) were intimately mixed with LSGM and fired at $1150^{\circ} \mathrm{C}$ for $1 \mathrm{~h}$. The XRD patterns are shown in Fig. 10. For the SCF, which has zero La activity, the phase $\mathrm{LaSrGa}_{3} \mathrm{O}_{7}$ (the most intense peak is located at $2 \theta \approx 30^{\circ}$ ) is clearly seen in the matrix of cubic phases belonging to the LSGM and the SCF, indicating a La diffusion into the SCF. Although we did not prepare the sample that has a higher La content than that in the LSGM, the phase $\mathrm{LaSrGaO}_{4}$ is expected at the interface if La diffusion into the LSGM is allowed to occur. Only at the equal La concentration, LSCo20, would we expect no impurity phases to be found. This study suggests use of the LSCo20 or another iso-La concentration perovskite as the cathode material to insure chemical stability. Indeed, the LSCN $\left(x_{\mathrm{La}}=0.80\right.$, see Table I) showed a comparable overpotential to that of the $\mathrm{SCF}$ at $800^{\circ} \mathrm{C}$ in Fig. 8. However, it was found that the SCF cathode outperformed

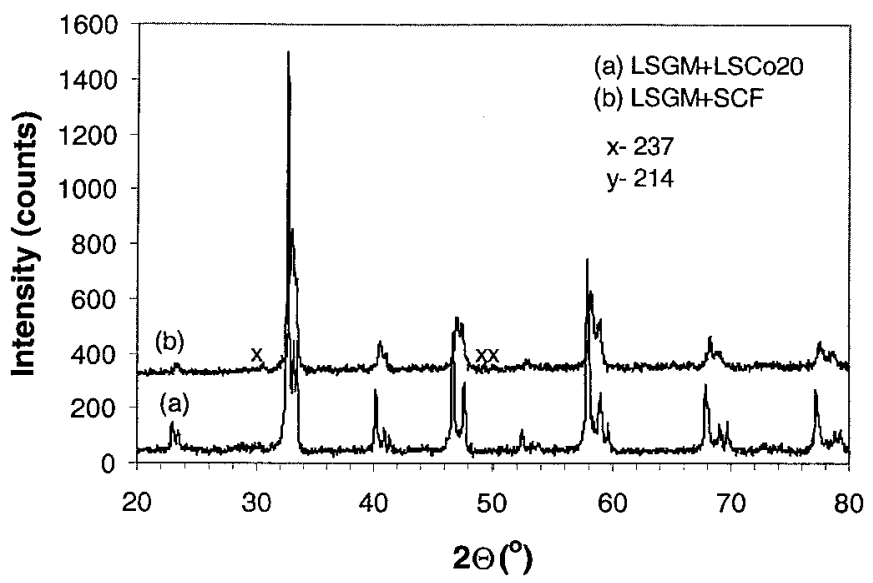

Figure 10. XRD patterns from (a) the mixture of $\mathrm{La}_{0.8} \mathrm{Sr}_{0.2} \mathrm{CoO}_{3-\delta}$ (LSCo20) and LSGM (1:1 wt \%) after firing at $1150^{\circ} \mathrm{C}$ for $1 \mathrm{~h}$. (b) The mixture of SCF and LSGM (1:1 wt \%) after firing at $1150^{\circ} \mathrm{C}$ for $1 \mathrm{~h}$. All unmarked peaks represent the main phases LSGM, LSCo20, and SCF. 


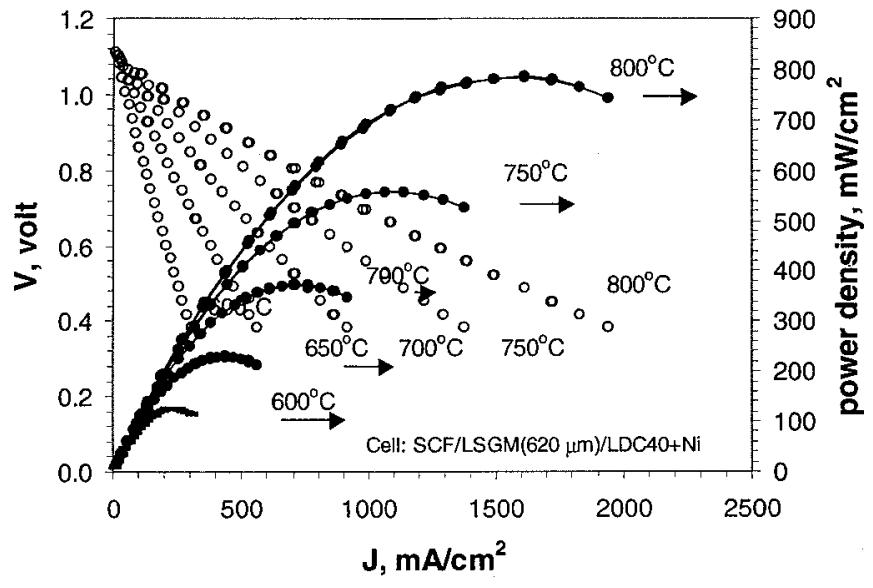

Figure 11. Cell voltage and power density as a function of current density at various temperatures. The cell consists of air, SCF/LSGM/LDC40 $+\mathrm{Ni}$, $\mathrm{H}_{2}+3 \% \mathrm{H}_{2} \mathrm{O}$. The LSGM thickness is $620 \mu \mathrm{m}$.

the LSCN cathode at lower temperatures. Again, a trade-off between chemical reactivity and electrocatalytic activity must be made to achieve the best performance. If a target operating temperature for a SOFC is set to be $800^{\circ} \mathrm{C}$, our newly developed cathode material LSCN should be the best choice of cathode material in terms of chemical stability, electrochemical activity and mechanical stability $\left(\mathrm{TEC}=15 \times 10^{-6} / \mathrm{K}\right.$ for the $\mathrm{LSCN}$ vs. $24 \times 10^{-6} / \mathrm{K}$ for the $\mathrm{SCF})$. Because the focus of this study was to investigate the chemical reactions occurring at the anode, SCF was used as a standard cathode material throughout the cell tests.

Single-cell performance.-The thick-film LSGM-based single-cell performance with SDC20/SDC20 + NiO anode and LSCo40 cathode was first reported to achieve in an air- $\mathrm{H}_{2}$ cell a maximum power density (MPD) of $550 \mathrm{~mW} / \mathrm{cm}^{2}$ at $800^{\circ} \mathrm{C} .^{5}$ At the same temperature and equivalent electrolyte thickness, the MPD was further increased to $700 \mathrm{~mW} / \mathrm{cm}^{2}$ with an SCF cathode. ${ }^{6}$ In the following, we report an even further enhancement of cell performance by improving the anode/electrolyte interface.

Figure 11 shows the V-J and P-J curves at different temperatures with our new anode LDC40 $+\mathrm{NiO}$ composite. No interlayer was applied in this cell. For a $620 \mu \mathrm{m}$ thick LSGM electrolyte, the MPD was expectedly increased to $800 \mathrm{~mW} / \mathrm{cm}^{2}$ at $800^{\circ} \mathrm{C}$; it was 100 $\mathrm{mW} / \mathrm{cm}^{2}$ at $600^{\circ} \mathrm{C}$.

As indicated above, the La diffusion through the anode/ electrolyte interface can be prevented with the LDC40 $+\mathrm{NiO}$ anode, but the interaction between $\mathrm{La} / \mathrm{Ga}$ and $\mathrm{Ni}$ remains to occur if the anode is fired at elevated temperatures. A straightforward solution to prevent this reaction is to place an LDC40 interlayer between the LSGM and the composite NiO-containing anode. The mixed conductivity of the LDC40 thin film provided no block to the transport of oxide ions across the cell in reducing atmospheres. The cell performance with the interlayer as a function of current density at different temperatures is shown in Fig. 12. With the aid of the interlayer, we were able to achieve an MPD close to 900 and 150 $\mathrm{mW} / \mathrm{cm}^{2}$ at 800 and $600^{\circ} \mathrm{C}$, respectively. The significant reduction in the anode overpotential with and without the interlayer has been demonstrated in Fig. 7. The overall cell ASRs of both standard and interlayered cells estimated from the slope of the V-J curves from 600 to $800^{\circ} \mathrm{C}$ are listed in Table II. For comparison, the ASR values of an old cell with SDC20 $+\mathrm{NiO}$ anode are also listed in the table. Although the $\mathrm{La}_{2} \mathrm{O}_{3}$-doped $\mathrm{CeO}_{2}$ has a relatively lower conductivity than the $\mathrm{Sm}_{2} \mathrm{O}_{3}$-doped $\mathrm{CeO}_{2}$ under a given temperature and partial pressure of oxygen, ${ }^{31}$ it is more important, from a practical standpoint, to avoid the unwanted chemical reactions occurring at the

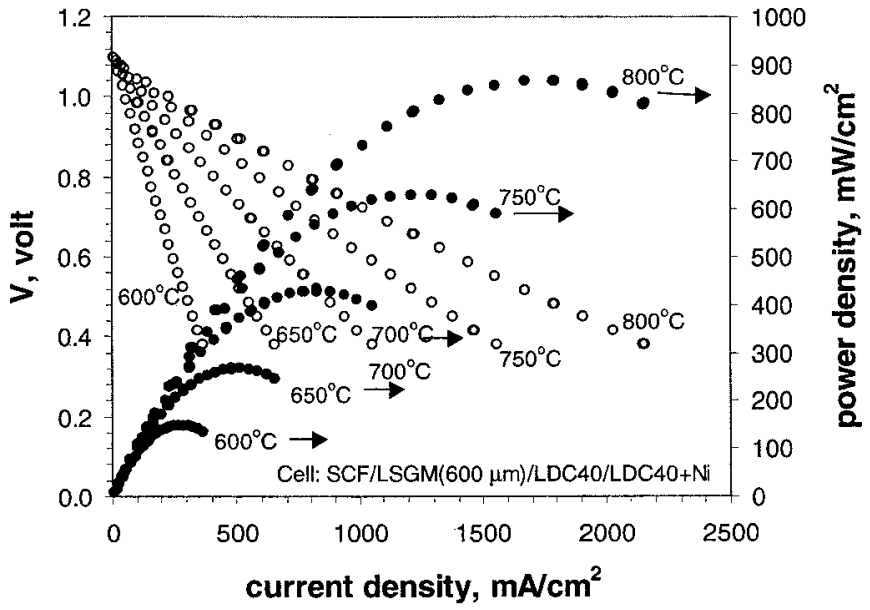

Figure 12. Cell voltage and power density as a function of current density at various temperatures. The cell consists of air, SCF/LSGM/LDC40/LDC40 $+\mathrm{Ni}, \mathrm{H}_{2}+3 \% \mathrm{H}_{2} \mathrm{O}$. The LSGM thickness is $600 \mu \mathrm{m}$.

electrolyte/electrode interfaces than to optimize the oxide-ion conduction in doped $\mathrm{CeO}_{2}$.

Note that the cell open-circuit voltages (OCV) at a given temperature in the above two cells is very close to the Nernst potential determined by the equation $\mathrm{OCV}=(R T / 4 F)\left[\ln \left(0.21 / P o_{2}^{\prime \prime}\right)\right]$, where $P o_{2}^{\prime \prime}$ is fixed by the $\mathrm{H}_{2} \mathrm{O}$ to $\mathrm{H}_{2}$ ratio at a given temperature. This result indicates good cell sealing. In addition, decreasing the cell temperature increases the cell OCV. This could be a direct indication of pure ionic conduction occurring in the electrolyte since $\ln \left(0.21 / P o_{2}^{\prime \prime}\right)$ increases with decreasing temperature at a faster rate than the temperature decreases if electronic conduction is negligible in the electrolyte.

Long-term performances of both noninterlayered and interlayered cells under a loading current density of $250 \mathrm{~mA} / \mathrm{cm}^{2}$ were recorded at $800^{\circ} \mathrm{C}$ as a function of time, see Fig. 13a and b. The anode of the noninterlayered cell, Fig. 13a, showed a higher overpotential than that of its cathode partner. The cell voltage decayed slightly with time as a result of a small increase of anode overpotential. The chemical reaction between the LSGM and NiO mentioned above is a good reason for the observed degradation. In contrast, the cell voltage of the interlayered cell showed no sign of decay over 2 weeks. Both cathode and anode overpotentials were low and stable, indicating a good electrolyte/anode interface was achieved by introduction of the interlayer.

\section{Conclusions}

Chemical reactions at elevated temperatures between the LSGM, $\mathrm{CeO}_{2}$, and $\mathrm{NiO}$ have been studied primarily by XRD. The results showed that La is a fairly mobile species in the LSGM electrolyte. The La diffusion driven by the gradient of activity can alter the composition of the LSGM, leading to the formation of resistive phases, either $\mathrm{LaSrGa}_{3} \mathrm{O}_{7}$ or $\mathrm{LaSrGaO}_{4}$, at the electrolyte/electrode interfaces depending on whether La diffuses out of or into the LSGM, respectively. As a result, the SDC20 anode showed sensitivity to the preparation conditions, and a lower cell power density with a higher anode overpotential was commonly observed. To al-

Table II. Comparison of ASR values $\left(\Omega \mathrm{cm}^{2}\right)$ from interlayered and standard cells.

\begin{tabular}{lccc} 
& $800^{\circ} \mathrm{C}$ & $700^{\circ} \mathrm{C}$ & $600^{\circ} \mathrm{C}$ \\
\hline Interlayered cell (LDC40 anode) & 0.34 & 0.70 & 2.07 \\
Standard cell (LDC40 anode) & 0.39 & 0.84 & 2.58 \\
Standard cell (SDC20 anode) & 0.44 & 1.02 & 3.06
\end{tabular}



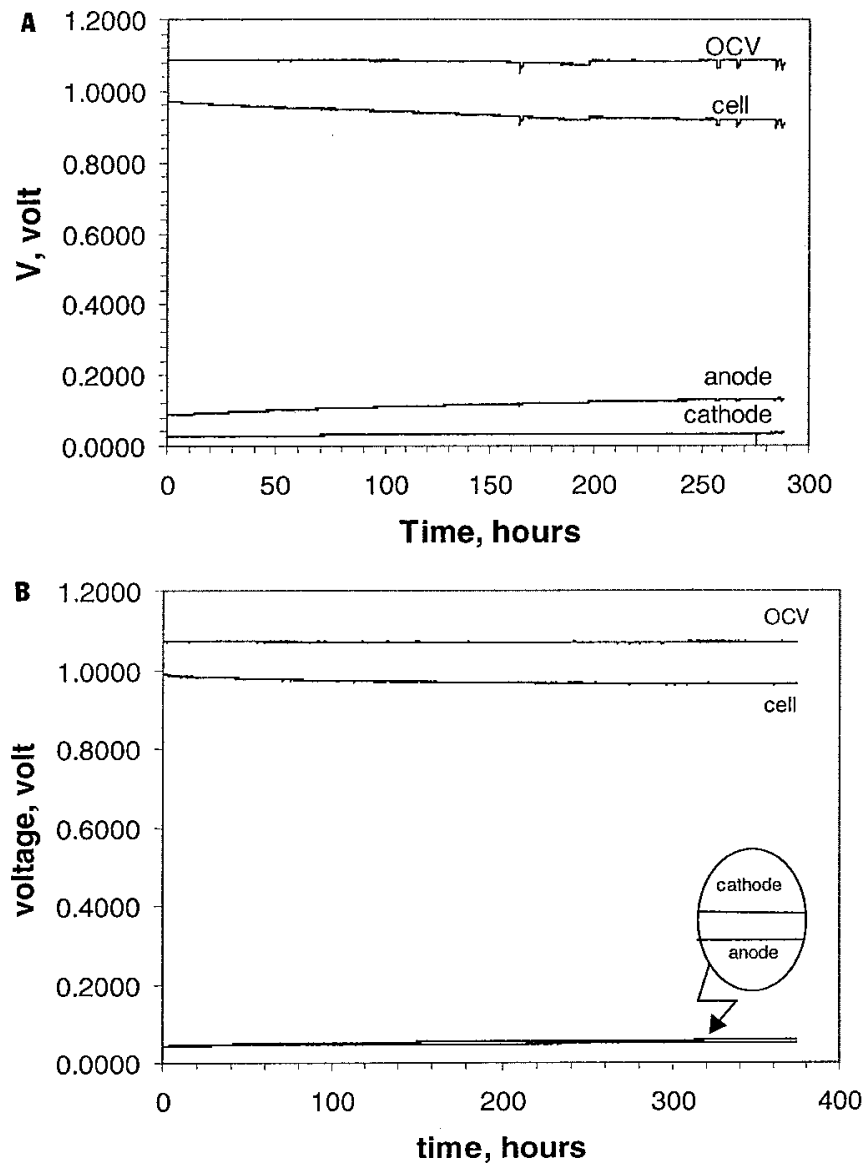

Figure 13. Long-term performance of single LSGM-based fuel cells (a) without and (b) with an interlayer.

leviate this problem, a concept of an iso-La chemical activity fuel cell was proposed and practiced in the anode composition. Use of a $40 \mathrm{~mol} \% \mathrm{La}_{2} \mathrm{O}_{3}$-doped $\mathrm{CeO}_{2}$ (LDC40), which has an identical $\mathrm{La}$ concentration to that in the LSGM, in place of the SDC20 in the NiO-containing composite anode produced a much lower anode overpotential and increased the MPD to $800 \mathrm{~mW} / \mathrm{cm}^{2}$ at $800^{\circ} \mathrm{C}$. In addition, the interactions between the LSGM and $\mathrm{NiO}$ were likely to occur at high temperatures. To prevent this unwanted reaction, a $\mathrm{Ni}$-free LDC40 interlayer was introduced between the LSGM and LDC40 + NiO anode. Consequently, the anode overpotential was further lowered and the MPD of a cell with a $600 \mu \mathrm{m}$ thick LSGM electrolyte was increased to nearly $900 \mathrm{~mW} / \mathrm{cm}^{2}$ at $800^{\circ} \mathrm{C}$. Longterm monitoring of the cell performance under a loading current density of $250 \mathrm{~mA} / \mathrm{cm}^{2}$ at $800^{\circ} \mathrm{C}$ indicted no sign of decay in the cell voltage of the interlayered cell. Both anode and cathode overpotentials were shown to be low and stable. Overall, the mixed conductor SCF cathode exhibited consistently satisfactory performance in cell test, but La diffusion at the cathode/electrolyte interface, as occurs in the absence of an interlayer at the anode/ electrolyte interface, is a potential problem needing further investigation. Interdiffusion of $\mathrm{Ga}$ and $\mathrm{Co}$ across the cathode may also pose a serious problem with a thinner electrolyte. This can be exemplified by the data presented in this study. From individual voltage contributions from anode, cathode, and overall cell at a given current density $J=1.5 \mathrm{~A} / \mathrm{cm}^{2}$, the electrolyte area specific resistance is $0.11 \Omega \mathrm{cm}^{2}$ at $800^{\circ} \mathrm{C}$. Given the measured ionic conductivity of LSGM is $0.15 \mathrm{~S} / \mathrm{cm}$ at the same temperature, the effective electrolyte thickness is only $160 \mu \mathrm{m}$, not the $600 \mu \mathrm{m}$ of the electrolyte disk. The Co diffusion into the LSGM has created a conducting phase that penetrates from the cathode toward the anode to reduce the true LSGM thickness. Once these potential problems have been addressed in further studies, commercialization of the LSGM-based SOFCs would appear to be feasible in the near future.

\section{Acknowledgment}

The authors thank the Electric Power Research Institute (EPRI) and the Robert Welch Foundation for financial support in this project.

The University of Texas at Austin assisted in meeting the publication costs of this article.

\section{References}

1. T. Ishihara, H. Matsuda, and Y. Takita, J. Am. Chem. Soc., 116, 3801 (1994).

2. M. Feng and J. B. Goodenough, Eur. J. Inorg. Chem., T31, 663-72 (1994).

3. M. Feng, J. B. Goodenough, K. Huang, and C. Milliken, J. Power Sources, 63, 47 (1996).

4. K. Huang, M. Feng, J. B. Goodenough, and C. Milliken, J. Electrochem. Soc., 144, 3460 (1997).

5. K. Huang, R. Tichy, J. B. Goodenough, and C. Milliken, J. Am. Ceram. Soc., 81, 2581 (1998).

6. K. Huang, J. Wan, and J. B. Goodenough, J. Mater. Sci., 36, 1093 (2001).

7. K. Huang and J. B. Goodenough, J. Alloys Compd., 303, 454 (2000).

8. Y. Hiei, T. Ishihara, and Y. Takita, Solid State Ionics, 86-88, 1267 (1996).

9. R. Maric, S. Ohara, T. Fukui, H. Yoshida, M. Nishimura, T. Inagaki, and K. Miura, J. Electrochem. Soc., 146, 2006 (1999).

10. T. Inagaki, K. Miura, H. Yoshida, R. Maric, S. Ohara, X. Zhang, K. Mukai, and T. Fukui, J. Power Sources, 86, 347 (2000).

11. X. Zhang, S. Ohara, R. Maric, K. Mukai, T. Fukui, H. Yoshida, M. Nishimura, T. Inagaki, and K. Miura, J. Power Sources, 83, 170 (1999).

12. S. Ohara, R. Maric, X. Zhang, K. Mukai, T. Fukui, H. Yoshida, T. Inagaki, and K. Miura, J. Power Sources, 86, 455 (2000).

13. T. Kawada and H. Yokokawa, Key Eng. Mater., 125-126, 187 (1997).

14. M. J. L. Ostergard, C. Clausen, C. Bagger, and M. Morgensen, Electrochim. Acta, 40, 1971 (1995).

15. C. Tanner, K.-Z. Fung, and A. Virkar, J. Electrochem. Soc., 144, 21 (1997).

16. M. Hrovat, A. Ahmad-Khanlou, Z. Samardzija, and J. Holc, Mater. Res. Bull., 34, 2027 (1999).

17. M. Hrovat, J. Holc, and S. Bernik, J. Mater. Res., 14, 1692 (1999).

18. M. Hrovat, J. Holc, S. Bernik, and D. Makovec, Mater. Res. Bull., 33, 1175 (1998).

19. M. Hrovat, J. Holc, Z. Samardzija, and S. Bernik, J. Mater. Sci., 19, 233 (2000).

20. M. Hrovat, Z. Samardzija, J. Holc, and S. Bernik, J. Mater. Res., 14, 4460 (1999).

21. K. Huang, R. Tichy, and J. B. Goodenough, J. Am. Ceram. Soc., 81, 2565 (1998).

22. K. Huang and J. B. Goodenough, J. Solid State Chem., 136, 274 (1998).

23. E. Perry Murray, T. Tsai, and S. A. Barnett, Nature, 400, 649 (1999).

24. J. Faber, C. Geoffroy, A. Roux, A. Sylvestre, and P. Abelard, Appl. Phys. A: Solids Surf., 49, 225 (1989).

25. H. E. Höfer and W. F. Kock, J. Electrochem. Soc., 140, 2889 (1993).

26. H. E. Höfer and R. Schmidberger, J. Electrochem. Soc., 141, 782 (1994).

27. H. Obayashi and T. Kudo, Jpn. J. Appl. Phys., 14, 330 (1975).

28. S. B. Adler, Solid State Ionics, 111, 125 (1998).

29. S. B. Adler, J. A. Lane, and B. C. H. Steele, J. Electrochem. Soc., 143, 3554 (1996).

30. K. Huang and J. B. Goodenough, J. Electrochem. Soc., 148, E203 (2001).

31. H. Yahiro, Y. Eguchi, K. Eguchi, and H. Arai, J. Appl. Electrochem., 18, 527 (1988). 